\title{
Mixed germ cell-sex cord-stromal tumor with a concurrent interstitial cell tumor in a ferret
}

\author{
Saki INOUE ${ }^{1)}$, Kayoko YONEMARU ${ }^{1,2)}$, Tokuma YANAI ${ }^{1)}$ and Hiroki SAKAI ${ }^{1,2) *}$ \\ ${ }^{1)}$ Laboratory of Veterinary Pathology, Faculty of Applied Biological Sciences, Gifu University, 1-1 Yanagido, Gifu 501-1193, Japan \\ ${ }^{2)}$ Comparative Cancer Center, Faculty of Applied Biological Sciences, Gifu University, 1-1 Yanagido, Gifu 501-1193, Japan
}

(Received 25 August 2014/Accepted 25 September 2014/Published online in J-STAGE 13 October 2014)

ABSTRACT. A 5-year-old male ferret presented with an enlarged canalicular testis in the left inguinal region. Microscopically, the enlarged testis consisted of a diffuse intimately admixed proliferation of c-kit-positive germ cell-like and Wilms tumor-1 protein-positive Sertoli cell-like components, but no Call-Exner body was detected. In addition, the compact proliferation of steroidogenic acute regulatory proteinintense positive interstitial cells was identified in a separate peripheral area of the mass. Based on histopathological and immunohistochemical findings, the tumor was diagnosed as a mixed germ cell-sex cord-stromal tumor with a concurrent interstitial cell tumor.

KEY WORDS: ferret, immunohistochemistry, interstitial cell tumor, mixed germ cell-sex cord-stromal tumor, testis

doi: 10.1292/jvms.14-0435; J. Vet. Med. Sci. 77(2): 225-228, 2015

Although neoplastic diseases in ferrets have been reported in various organs, testicular tumors in ferrets are very rare [5, $9,11]$ due to the common practice of early neutering in male ferrets [1]. In fact, there are only four reports of testicular tumors in ferrets including interstitial cell tumors, a Sertoli cell tumor with an interstitial cell tumor and a benign peripheral nerve sheath tumor $[1,3,4,10]$. Here, we report the pathological features of a mixed germ cell-sex cord-stromal tumor (MGSCT) with a concurrent interstitial cell tumor in a ferret.

A 5-year-old male ferret in good general condition was admitted to a veterinary hospital for medical follow up on an enlarged spleen and adrenal gland. Upon examination, a mass was found in the left inguinal region, which was suspected to be an undescended testis, as only one testis was detected in the scrotum. The mass and the remaining testis were surgically removed, and the ferret did not exhibit any evidence of tumor recurrence or metastasis following surgery. The enlarged spleen and adrenal gland were not examined according to an owner's intention.

The left testis was fixed in 10\% neutral buffered formalin, embedded in paraffin wax and processed for routine histological sectioning. The resulting sections were stained with hematoxylin and eosin (H\&E) and periodic acid-Schiff stain (PAS). For immunohistochemistry, the sections were labeled using the peroxidase-conjugated immune polymer method (Envision; Dako, Glostrup, Denmark). Primary antibodies to c-kit (Dako,; 1/250 dilution), Wilms tumor-1 protein (WT-1, Santa Cruz Biotechnology, Dallas, TX, U.S.A.; 1/500 dilu-

*Correspondence to: Sakai, H., Laboratory of Veterinary Pathology, Faculty of Applied Biological Sciences, Gifu University, 1-1 Yanagido, Gifu 501-1193, Japan. e-mail: shiroki@gifu-u.ac.jp (C2015 The Japanese Society of Veterinary Science

This is an open-access article distributed under the terms of the Creative Commons Attribution Non-Commercial No Derivatives (by-nc-nd) License $<$ http://creativecommons.org/licenses/by-nc-nd/3.0/>. tion) and steroidogenic acute regulatory protein (StAR, Santa Cruz Biotechnology; 1/300 dilution) were used to label for germ cells, Sertoli cells and interstitial cells, respectively. The sections were dewaxed, and heat induced antigen retrieval was performed using the Target retrieval solution (Dako, pH 6.0 for c-kit and WT-1, high pH for StAR) at $121^{\circ} \mathrm{C}$ for $1 \mathrm{~min}$. The results of preliminary validation of cross-immunoreactivity using normal ferret testis indicated that the expression of c-kit and WT-1 was specific to germ cells and Sertoli cells, respectively [6, 16] (Figs. 5 and 6). Intense immnunoreactivity of StAR was observed in interstitial cells, and Sertoli cells were also slightly positive for StAR [6, 14] (Fig. 7).

Gross examination revealed that the tumor was $6.5 \times 5.5$ $\mathrm{cm}$ in size, firm and irregularly round in shape. The cut surface revealed whitish yellow, partially brown and dark red areas which was suspected as hemorrhage (Fig.1). Likewise, a number of cystic cavities were observed at the cut surface.

The histopathological results revealed that the left testis was replaced entirely by neoplastic tissue. The neoplasm consisted of a diffuse intimately admixed proliferation of germ cell-like cells and Sertoli cell-like cells (Figs. 2 and 3). The former were large round cells that possessed abundant clear cytoplasm, large round to ovoid nuclei with one or two prominent large nucleoli and c-kit positive membranes (Fig. 8 ). The latter were spindle to polygonal cells that exhibited scant cytoplasm, oval to spindle nuclei including obvious nucleoli and WT-1 positive nuclei (Fig. 9). These cells proliferated diffusely in most areas. Mitotic figures were observed in germ cell populations, but infiltration of neoplastic cells into the tunica albuginea was not observed. Likewise, a structure resembling a Call-Exner body, which is PASpositive material centered in rosette-structures consisting of Sertoli-like cells, was not identified.

In the peripheral area of the testicular mass, another component consisting of cells with abundant granular weakly eosinophilic cytoplasm and round to oval, small nuclei were 

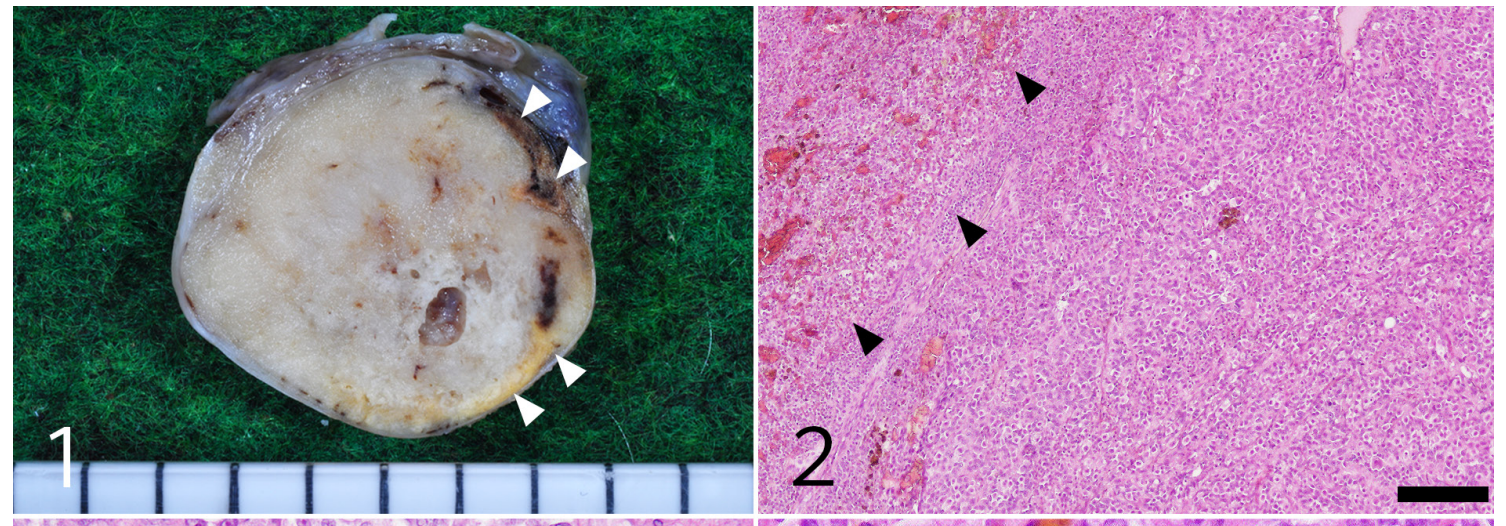

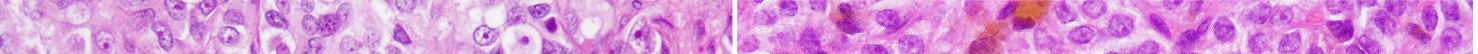

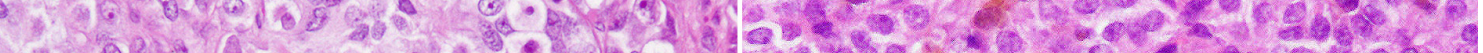

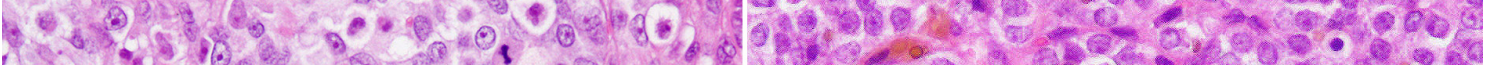

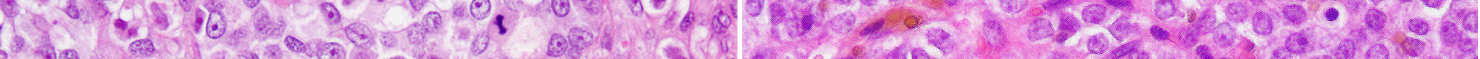

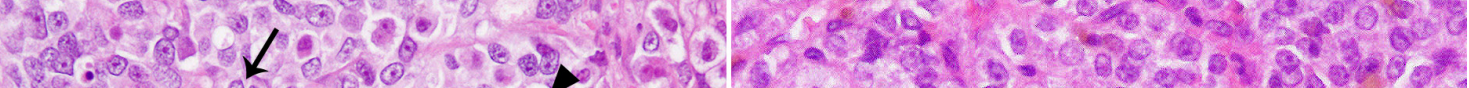

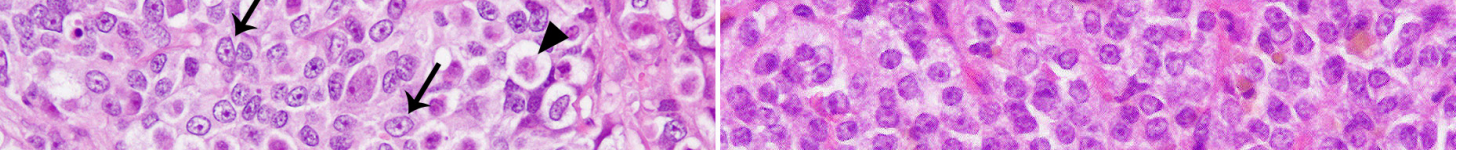

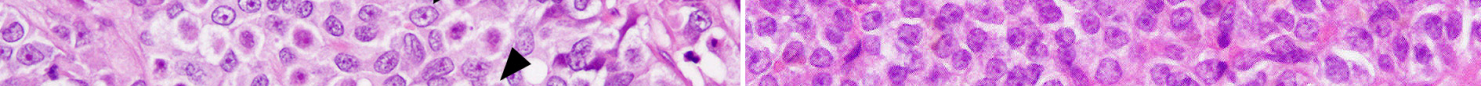

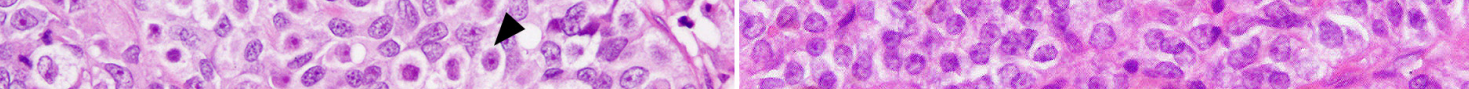

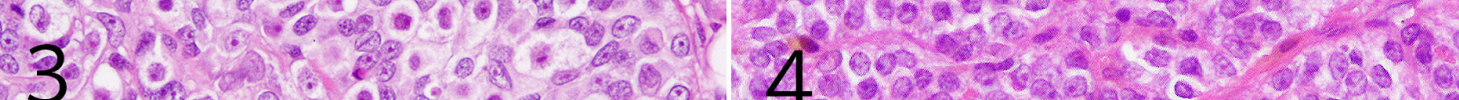

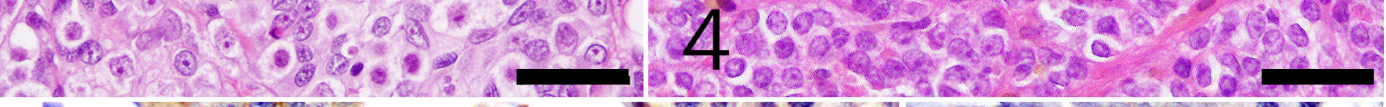

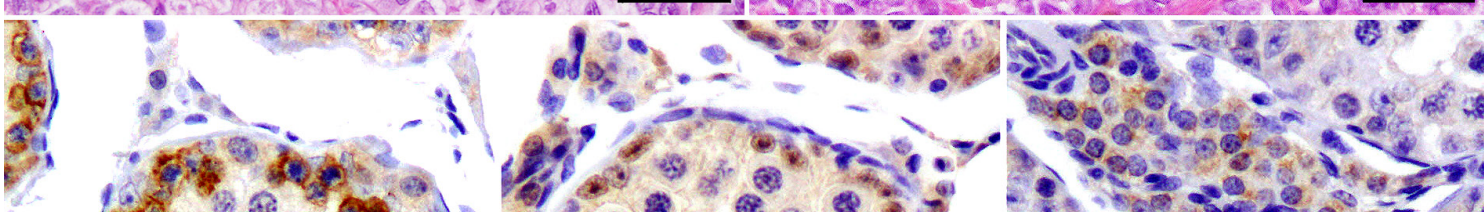

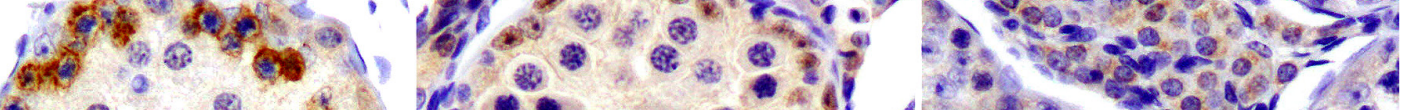

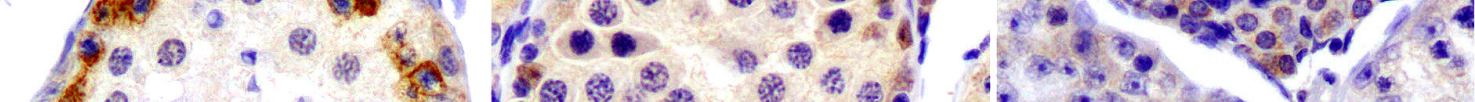

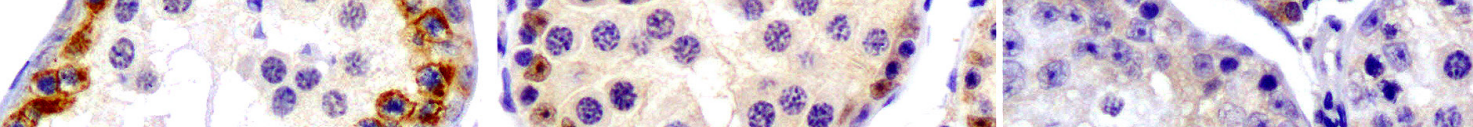

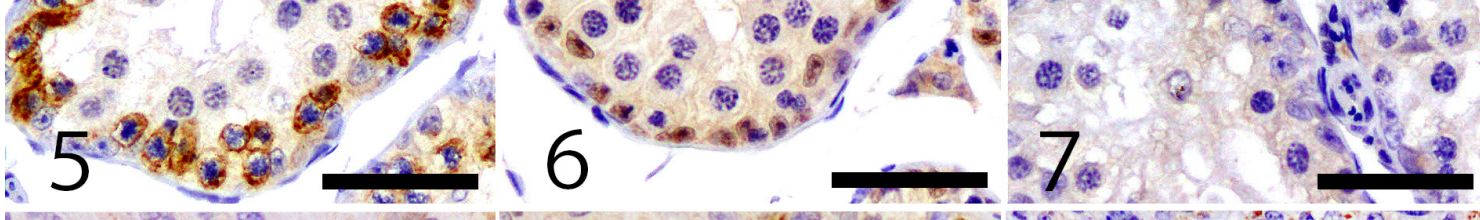

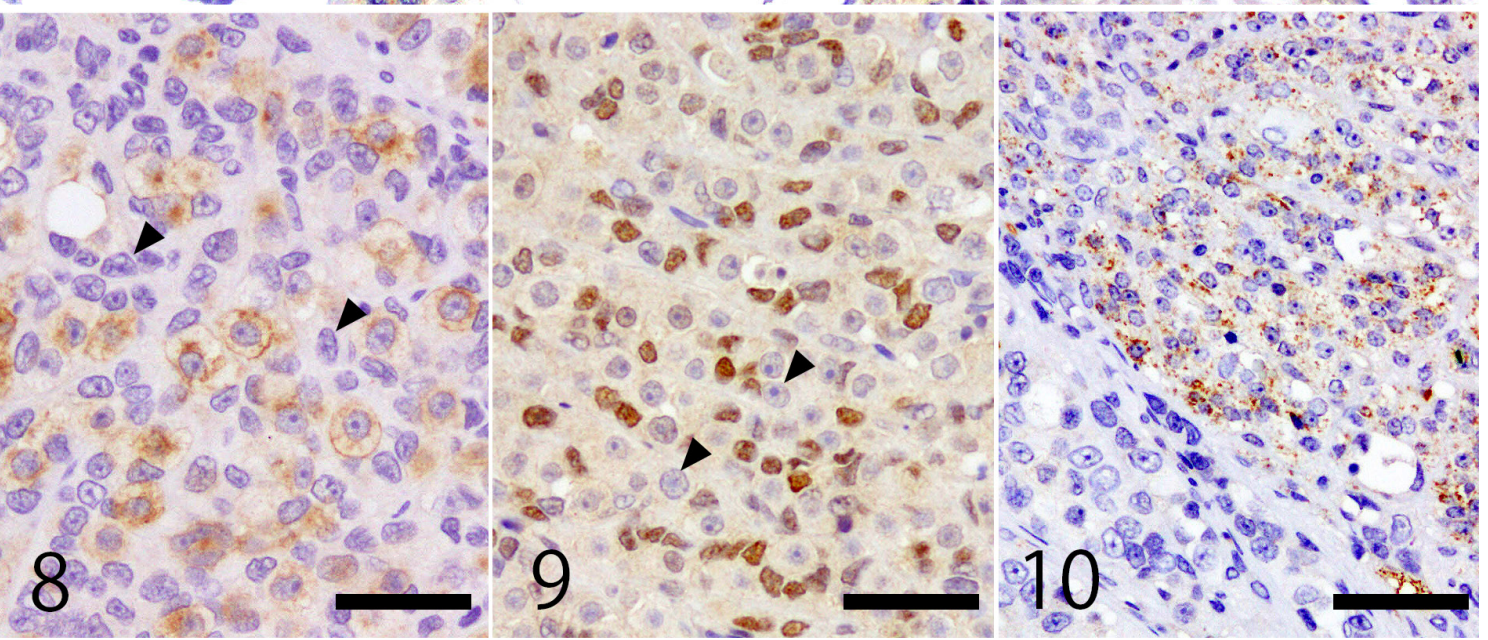


detected. Proliferation of these cells were divided into compact nests by fine vascular connective tissues that contained evidence of hemorrhage (Fig. 4). The cells were devoid of mitotic figures and exhibited StAR-intense positive cytoplasmic granules, but negative for c-kit and WT-1 following immunohistochemistry (Fig. 10). Further, the boundary between MGSCT and this proliferation was distinct. Based on the morphological and immunohistochemical results, proliferation of those cells was identified as an interstitial cell tumor.

Histological and immunohistochemical findings indicated that the testicular mass in the present case consisted of an admixture of the tumor cells originating from germ cells and from the sex-cord driven cells concurrent with an interstitial cell tumor. Testicular tumors in domestic animals are classified as germ cell tumors sex cord-stromal tumors, and MGSCT, but MGSCT is very rare [8]. The neoplasm characterized by intimately mixed germ cells and sex cord stromal cells has been divided into MGSCT and gonadoblastoma. In humans, gonadoblastomas consist of discrete nests separated by fibrous stroma containing Call-Exner bodies or calcified foci [15]. Though gonadoblastomas are not included in the World Health Organization classification of tumors that occur in domestic animals, detection of gonadoblastomas has been reported in two canines, two rabbits and in a lesser galago $[7,8,16]$. On the other hand, MGSCTs typically consist of diffuse admixed proliferation of two cell types, and Call-Exner bodies are usually absent [17]. The present case consisted of various sizes of irregular nests containing germ cell and Sertoli cell components. However, there were neither Call-Exner bodies nor any calcified foci, and thus, the tumor was diagnosed as a MGSCT.

In humans, two thirds of gonadoblastomas contain various amounts of interstitial cell component, and gonadoblastomas reported in a stallion have described that an MGSCT contained foci of interstitial cells that were considered in- terstitial cell-differentiation of neoplastic sex cord-stromal cell components $[2,4,15]$. Further, two cases of concurrent MGSCT and interstitial cell tumors have been reported in canines $[12,13]$. In the present case, gross and histopathological findings indicated that the proliferation of interstitial cells was located outside the neoplastic tissue and was compressed by the MGSCT. In addition, no proliferation of germ cells and Sertoli cells was noted in the proliferating area of the interstitial cells. Thus, the proliferation of the interstitial cells was considered a concurrent tumor rather than a neoplastic component of the MGSCT.

To our knowledge, the present case is the first report of a MGSCT with an associated interstitial cell tumor occurring in the testis of a ferret.

\section{REFERENCES}

1. Batista-Arteaga, M., Suárez-Bonnet, A., Santana, M., Niño, T., Reyes, R. and Alamo, D. 2011. Testicular neoplasms (interstitial and Sertoli cell tumours) in a domestic ferret (Mustela putorius furo). Reprod. Domest. Anim. 46: 177-180. [Medline] [CrossRef]

2. Brito, L. F., Engiles, J. B., Turner, R. M., Getman, L. M. and Ebling, A. 2009. Bilateral testicular mixed germ cell-sex cord-stromal tumours in a stallion. Reprod. Domest. Anim. 44: 846-851. [Medline] [CrossRef]

3. Carpenter, J. W. and Novilla, M. N. 1977. Diabetes mellitus in a black-footed ferret. J. Am. Vet. Med. Assoc. 171: 890-893. [Medline]

4. Cullen, J. M., Whiteside, J., Umstead, J. A. and Whitacre, M. D. 1987. A mixed germ cell-sex cord-stromal neoplasm of the testis in a stallion. Vet. Pathol. 24: 575-577. [Medline]

5. Dillberger, J. E. and Altman, N. H. 1989. Neoplasia in ferrets: eleven cases with a review. J. Comp. Pathol. 100: 161-176. [Medline] [CrossRef]

6. Gentil, M., Hoffmann, B., Spang, A., Failing, K. and GoerickePesch, S. 2012. Restart of steroidogenesis in dogs during recrudescence of testicular function following downregulation with a GnRH-agonist implant. Cell Tissue Res. 350: 513-523.

Fig. 1. Gross findings. The cut surface revealed pale yellow, partially tan to brown or dark red areas, which corresponded to interstitial tumor cells (arrowheads). Some cystic cavities were also observed. Scale $=5 \mathrm{~mm}$.

Fig. 2. Histopathological findings of the tumor. The neoplasm consisted of diffuse proliferation of intimately admixed germ cell-like cells and Sertoli cell-like cells. Interstitial cell tumor (arrowheads) was compressed by MGSCT. Bar $=200 \mu \mathrm{m}$.

Fig. 3. Histopathological findings of MGSCT. Diffuse proliferation of large round germ cells characterized by abundant clear cytoplasm and large round to ovoid nuclei with one or two prominent large nucleoli (arrowheads) and spindle to polygonal Sertoli cells with scant cytoplasm and oval to spindle nuclei including obvious nucleoli (arrows). Mitoses were scattered. Bar $=50 \mu \mathrm{m}$.

Fig. 4. Histopathological findings of interstitial cell tumor. Proliferation of interstitial cells with abundant granular weakly eosinophilic cytoplasm and round to oval, small nuclei divided into compact nests by fine vascular connective tissues. Mitotic figures were absent. Bar=25 $\mu \mathrm{m}$.

Fig. 5. Immunohistochemistry of c-kit in normal ferret testis. The spermatocytes were membranous positive in the cytoplasm. Bar=50 $\mu \mathrm{m}$.

Fig. 6. Immunohistochemistry of WT-1 in normal ferret testis. Nuclei of Sertoli cells were positive. Bar $=50 \mu \mathrm{m}$.

Fig. 7. Immunohistochemistry of StAR in normal ferret testis. The cytoplasmic granules of interstitial cells were intensely positive for StAR. Sertoli cells were also slightly positive for StAR. Bar $=50 \mu \mathrm{m}$.

Fig. 8. Immunohistochemistry of c-kit. Germ cells were membranous positive for c-kit in the cytoplasm. Sertoli cells were negative for c-kit (arrowheads). Bar $=50 \mu \mathrm{m}$.

Fig. 9. Immunohistochemistry of WT-1. Sertoli cells were nuclear positive for WT-1. Germ cells were negative for WT-1 (arrowheads). Bar=50 $\mu \mathrm{m}$.

Fig. 10. Immunohistochemistry of StAR. In the left lower area, germ cells and Sertoli cells were negative for StAR. In contrast, the cytoplasmic granules of interstitial cells were positive for StAR in the right upper area. The boundary between MGSCT and interstitial cell tumor was distinct. $\mathrm{Bar}=50 \mu \mathrm{m}$. 
[Medline] [CrossRef]

7. Irizarry Rovira, A. R., Lynch, S., David, M. and Ramos Vara, J. A. 2012. Gonadoblastoma in the ovaries of a lesser galago (Galago senegalensis braccatus). J. Comp. Pathol. 147: 204-208. [Medline] [CrossRef]

8. Kennedy, P. C., Cullen, J. M., Edwards, J. F., Goldschmidt, M. H., Larsen, S., Munson, L. and Nielsen, S. 1998. Histological classification of tumors of the genictal system of domestic animals, Armed forces institute of pathology, Washington, D. C.

9. Li, X., Fox, J. G. and Padrid, P. A. 1998. Neoplastic diseases in ferrets: 574 cases (1968-1997). J. Am. Vet. Med. Assoc. 212: 1402-1406. [Medline]

10. Meschter, C. L. 1989. Interstitial cell adenoma in a ferret. Lab. Anim. Sci. 39: 353-354. [Medline]

11. Miwa, Y., Kurosawa, A., Ogawa, H., Nakayama, H., Sasai, H. and Sasaki, N. 2009. Neoplasitic diseases in ferrets in Japan: a questionnaire study for 2000 to 2005. J. Vet. Med. Sci. 71: 397-402. [Medline] [CrossRef]

12. Owston, M. A. and Ramos-Vara, J. A. 2007. Histologic and immunohistochemical characterization of a testicular mixed germ cell sex cord-stromal tumor and a leydig cell tumor in a dog. Vet.
Pathol. 44: 936-943. [Medline] [CrossRef]

13. Patnaik, A. K. and Mostofi, F. K. 1993. A clinicopathologic, histologic, and immunohistochemical study of mixed germ cellstromal tumors of the testis in 16 dogs. Vet. Pathol. 30: 287-295. [Medline] [CrossRef]

14. Pollack, S. E., Furth, E. E., Kallen, C. B., Arakane, F., Kiriakidou, M., Kozarsky, K. F. and Strauss, J. F. 3rd. 1997. Localization of the steroidogenic acute regulatory protein in human tissues. J. Clin. Endocrinol. Metab. 82: 4243-4251. [Medline]

15. Scully, R. E. 1970. Gonadoblastoma. A review of 74 cases. Cancer 25: 1340-1356. [Medline] [CrossRef]

16. Suzuki, M., Ozaki, M., Ano, N., Nomura, K., Ozaki, K. and Narama, I. 2011. Testicular gonadoblastoma in two pet domestic rabbits (Oryctolagus cuniculus domesticus). J. Vet. Diagn. Invest. 23: 1028-1032. [Medline] [CrossRef]

17. Ulbright, T. M. 2004. Tumours containing both germ cell and sex cord/gonadal stromal elements. pp. 261-262. In: Pathology \& Genetics of Tumour of the Urinary System and Male Genital Organs, (Elbe J.E., Sauter G., Epstein J.I. and Sesterhenn I.A. eds.), IARC Press, Lyon. 